\title{
For Serena Williams, and my mother
}

Cite as: CMAJ 2019 December 2;191:E1337. doi: 10.1503/cmaj.190849

Black skin

White coat

No matter the lifetime, cotton hair is parted and shaved. The crowning

achievement of womanhood is the attention of the operating table,

legs splayed, an offering to nitrile glove and silver scope.

History dilating, she cries alongside her burgeoning womb, skin no thicker than her oppressors. She is her body and hundreds

of other bodies, slick in water, in light - a child, and a clot

to compress with black tulle, the uplifted gaze of the world.

Had ears opened, maybe her mothers would have guided her with a strength

that I am reminded warrants jealousy, irreducible to Latin.

But an eleven of ten remains a four.

\section{Terese Mason Pierre MA}

Toronto, Ont.

This article has been peer reviewed.

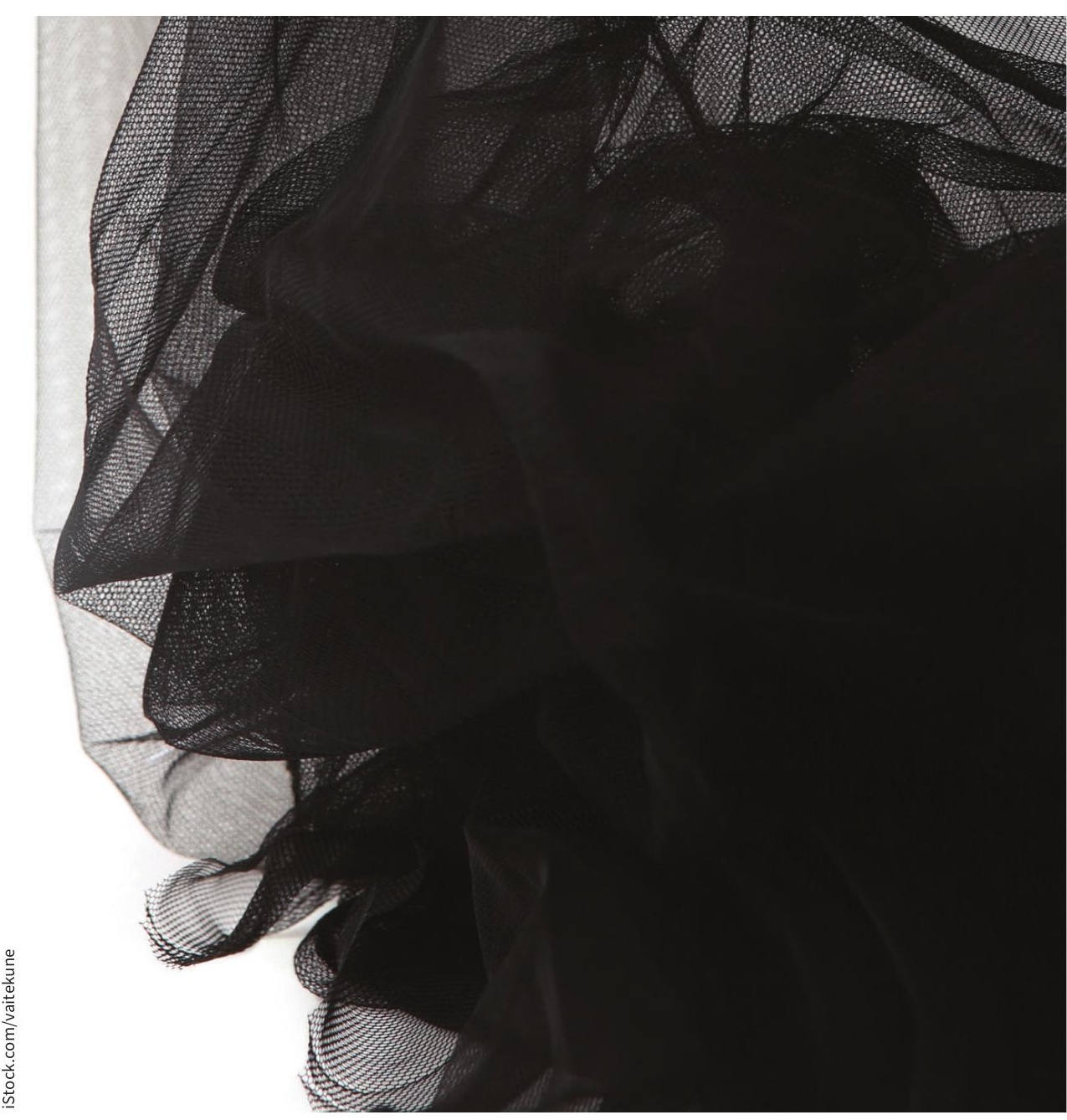

